\title{
Nutrientes no solo e produção de quiabo conforme doses de silicato de cálcio e magnésio
}

\author{
Emmerson Rodrigues de Moraes ${ }^{1}$, Aysha Cristinne dos Reis ${ }^{1}$, Nikson Elias Pinto da Silva ${ }^{1}$, \\ Mateus Ferreira ${ }^{1}$, Felipe Garcia de Menezes ${ }^{1}$ \\ ${ }^{1}$ Instituto Federal de Educação Ciência e Tecnologia Goiano, Campus Morrinhos, Morrinhos, Minas Gerais, Brasil. E-mail: \\ emmerson.moraes@ifgoiano.edu.br, ayshacristinne@gmail.com, nikson-silva@hotmail.com
}

Recebido:12/09/2017; Aceito: 29/01/2018

\begin{abstract}
RESUMO
A acidez do solo é fator limitante na agricultura, pelo fato da mesma indisponibilizar o fósforo na solução do solo e influenciar na dinâmica dos demais nutrientes no solo. A utilização de silicato de cálcio $(\mathrm{Ca})$ e magnésio $(\mathrm{Mg})$ fornece silício $(\mathrm{Si})$ e corrige a acidez do solo aumentando a produtividade. O objetivo do estudo foi observar a produção do quiabeiro e as características químicas do solo em função da aplicação de diferentes doses de silicato de cálcio e magnésio. Utilizou-se o delineamento em blocos casualizados com cinco tratamentos e cinco repetições cultivado em 2014 e 2016. O silicato de cálcio e magnésio foi aplicado ao solo nas seguintes doses: 0; 0,$5 ; 1,0 ; 2,0 \mathrm{e} \mathrm{4,0} \mathrm{tha}^{-1}$. Foram avaliados o peso de fruto por planta, peso médio de frutos, número de frutos por planta, produtividade, e os teores de $\mathrm{Si}, \mathrm{Ca}, \mathrm{Mg}$ e pH do solo. Não há acréscimos nos componentes do rendimento e produtividade do quiabeiro com o fornecimento de silicato de cálcio e magnésio em solo com boa fertilidade. $\mathrm{O}$ silicato de cálcio e magnésio reduz a acidez do solo e aumenta os teores de Ca, Mg e Si disponíveis no solo.
\end{abstract}

Palavras-chave: Abelmoschus esculentus, adubação silicatada, produtividade.

\section{Nutrients in the soil and okra production conforming application of calcium and magnesium silicate}

\begin{abstract}
Soil acidity is a limiting factor in agriculture, because it immobilizes phosphorus in the soil and influences the dynamics of other nutrients in the soil. The use of calcium and magnesium silicate as a corrective and supplier of $\mathrm{Si}, \mathrm{Ca}$ and $\mathrm{Mg}$ can improve the performance of the crop. The objective of the study was to observe the performance of the okra crop [Abelmoschus esculentus (L.) Moench] and soil properties as a function of the application of calcium and magnesium silicate. A randomized block design with five treatments and five replications was used. The calcium and magnesium silicate was applied to the soil in the following doses: 0; 0.5; 1.0; 2.0 and $4.0 \mathrm{t} \mathrm{ha}^{-1}$. The fruit weight per plant, average fruit weight, number of fruits per plant, productivity, $\mathrm{Si}$, $\mathrm{Ca}, \mathrm{Mg}$ and soil $\mathrm{pH}$ were evaluated. There was no increase in the yield and productivity components of the okra with increasing doses of calcium and magnesium silicate. Calcium and magnesium silicate promotes a reduction of soil acidity and increases $\mathrm{Ca}, \mathrm{Mg}$ and $\mathrm{Si}$ levels of the soil.
\end{abstract}

Key words: Abelmoschus esculentus, silicate fertilization, productivity 


\section{Introdução}

O quiabeiro Abelmoschus esculentus (L.) Moench, pertencente à família Malvaceae é uma hortaliça originária da África, muito adaptada às condições tropicais. O quiabeiro encontrou no Brasil as melhores condições para o seu crescimento e desenvolvimento. $\mathrm{O}$ clima quente e úmido é muito favorável sendo mais cultivado nas regiões Nordeste e Sudeste (BACHEGA et al, 2013), ao contrário do clima frio com dias curtos e noites longas onde não possui desenvolvimento favorável. O fruto do quiabeiro é rico em vitaminas A, B1 e C, além de fornecer cálcio (EMBRAPA, 2011a).

Para o cultivo do quiabo o solo deve estar livre de acidez do solo. O solo deve ser bem manejado, contendo os nutrientes ideais para a cultura, tais como NPK, Ca, Mg, e além destes, a adubação orgânica também pode trazer inúmeros benefícios.

Um dos minerais primários mais abundantes nos solos é o óxido de silício $\left(\mathrm{SiO}_{2}\right)$, constituindo a base da estrutura da maioria dos argilominerais. O $\mathrm{Si}$ é encontrado em solos tropicais basicamente na forma de quartzo, opala $\left(\mathrm{SiO}_{2} \cdot \mathrm{nH}_{2} \mathrm{O}\right)$ e outras formas nãodisponíveis às plantas. Em solos oxídicos a disponibilidade de silício é menor em função do estado avançado de intemperização. (CAMARGO et al., 2007). $\mathrm{O}$ processo de intemperização dos solos pode apresentar sérias limitações químicas para o desenvolvimento das plantas. Como consequência, a intemperização promove a elevada acidez dos solos, redução da capacidade de troca catiônica (CTC), diminuição da saturação por bases e grande capacidade para fixar fósforo (BARBOSA FILHO et al., 2001).

O Si auxilia na resistência das plantas a doenças e pragas, diminui a taxa de transpiração e participa do ciclo das plantas. Rodrigues et al. (2011) comentam que em plantas de arroz, a adubação com Si pode reduzir ou eliminar o número de aplicações com agrotóxicos durante o ciclo da cultura. Diante disso, uma barreira física é formada após a deposição do $\mathrm{Si}$ abaixo da cutícula, formando assim uma camada de sílica em maior proporção conferindo maior resistência à planta, dificultando a penetração e desenvolvimento de hifas de fungos (KORNDÖRFER et al., 2002). Para Korndörfer e Datnoff (1995) em algumas culturas o silício pode aparecer nas folhas de forma natural e a quantidade do mesmo irá depender da idade da folha, em folhas velhas aparecendo em maior quantidade do que em novas.

A deposição de Si nas plantas depende do solo, da espécie e variedade da mesma. O Si pode resultar também em uma rápida ativação dos mecanismos de defesa da planta, além dele pode atuar também como uma barreira química. A forma que o Si protege a planta é estimulando a produção de quitinases, peroxidases e através do acúmulo de lignina, todos na parede celular exercendo maior resistência e/ou tolerância (CAMARGO, 2016).

O Si é um elemento benéfico para Gramíneas e em hortaliças para algumas Fabaceáes, Asteraceáes e Brassicaceáes (LANA et al., 2002). Revisando o efeito do Si na tolerância das plantas aos estresses abióticos e bióticos, Camargo (2016) observou, em hortaliças, redução de doenças fúngicas nas culturas da abobrinha, batata, melão, pepino, pimentão e tomate. São raros os estudos científicos envolvendo o uso de corretivos na cultura do quiabeiro, principalmente corretivos contendo fonte silicatada.

O objetivo foi avaliar a produção do quiabeiro e as características químicas do solo em função da aplicação de diferentes doses de silicato de cálcio e magnésio.

\section{Material e Métodos}

Os experimentos foram realizados no ano de 2014 e 2016 no Instituto Federal Goiano (IF Goiano), campus Morrinhos-GO, com uma altitude aproximada de 850 metros. O solo foi classificado como Latossolo Vermelho Amarelo distrófico (EMBRAPA, 2013).

O clima da região, segundo Koppen, é tropical úmido, caracterizado por verão chuvoso e inverno seco. As temperaturas médias mensais de julho a novembro nos anos de 2014 e 2016 variaram de 18 a $24^{\circ}$ C. A precipitação média de julho a novembro de 2014 foi de $440 \mathrm{~mm}$ e no ano de 2016 nos mesmos meses foi de 400 $\mathrm{mm}$.

Amostras de solo foram coletadas nas profundidades de 0 a $20 \mathrm{~cm}$ e 20 a $40 \mathrm{~cm}$ e posteriormente encaminhadas ao laboratório para a análise química (Tabela 1) e física (Tabela 2).

$\mathrm{O}$ delineamento experimental foi em blocos casualizados em esquema fatorial 2 x 5, sendo dois anos de cultivo e cinco doses com cinco repetições. O cultivo ocorreu nos anos de 2014 e 2016 e as doses de silicato de cálcio e magnésio foram: $0 ; 0,5 ; 1,0 ; 2,0$ e 4,0 $\mathrm{t} \mathrm{ha}^{-1}$. Em julho de 2014 após a aplicação do silicato sobre a superfície do solo foi utilizada enxada rotativa com encanteirador para homogeinização. O Agrosilício Plus ${ }^{\circledR}$ foi a fonte do silicato de cálcio e magnésio tratando-se de um corretivo de solo e fertilizante mineral simples que possui $25 \%$ de cálcio, $6 \%$ de magnésio e $10,5 \%$ de silício.

As adubações de plantio e cobertura foram realizadas de acordo com a análise química do solo e as recomendações de Correia et al. (1999). Utilizou-se no plantio $400 \mathrm{~kg} \mathrm{ha}^{-1}$ da formulação 08-28-18 (20 $\mathrm{g}_{\text {planta }}{ }^{-}$ ${ }^{1}$ ) e em cobertura $200 \mathrm{~kg} \mathrm{ha}^{-1}$ da formulação 20-00-20 (10 g planta $\left.^{-1}\right)$, aos 20,50 e 80 dias após o transplante. 
Tabela 1. Caracterização química do solo da área experimental na profundidade de 0 a 20 e 20 a $40 \mathrm{~cm}$, em julho de 2014 , Morrinhos - GO.

\begin{tabular}{|c|c|c|c|c|c|c|c|c|c|c|}
\hline $\mathrm{pH}\left(\mathrm{H}_{2} \mathrm{O}\right)$ & $\mathrm{Ca}$ & $\mathrm{Mg}$ & $\mathrm{Al}$ & $\mathrm{P}$ & $\mathrm{K}$ & $\mathrm{H}+\mathrm{Al}$ & $\mathrm{T}$ & $\mathrm{V}$ & $\mathrm{m}$ & M.O. \\
\hline$---1: 2,5--$ & & $l_{c} \mathrm{dm}$ & & $--m$ & & $--\mathrm{cmol}$ & & ------ & & $-\mathrm{g} \mathrm{kg}^{-1}-$ \\
\hline 5,8 & 2,7 & 0,9 & 0,0 & 42,3 & 212 & 4,2 & 8,34 & 50 & 0 & 4,9 \\
\hline 5,9 & 1,9 & 0,5 & 0,0 & 16,5 & 76 & 3,2 & 5,79 & 45 & 0 & 3,3 \\
\hline
\end{tabular}

Tabela 2. Caracterização física do solo da área experimental na profundidade de 0 a 20 e 20 a 40 cm, Morrinhos - GO.

\begin{tabular}{cccccc}
\hline $\begin{array}{c}\text { Profundidade } \\
\mathrm{cm}\end{array}$ & AG & AF & Silte & Argila & Textura $^{1}$ \\
\hline 0 a 20 & 196 & 217 & 278 & 309 & Franco Argiloso \\
20 a 40 & 205 & 206 & 210 & 379 & Franco Argiloso \\
\hline
\end{tabular}

$\overline{\mathrm{AG}}=$ Areia grossa; $\mathrm{AF}=$ Areia fina. ${ }^{1-}$ Método da pipeta (EMBRAPA, 2011b).

Foi utilizada a cultivar Santa Cruz 47 e aos 30 dias após a aplicação dos tratamentos no início do mês de agosto de 2014 realizou-se o transplante das mudas de quiabo. Os canteiros formados obtiveram dimensões de $25 \mathrm{~cm}$ de profundidade, $1,30 \mathrm{~cm}$ de largura da base e $1,10 \mathrm{~cm}$ de largura de topo com espaçamento duplo de $0,8 \mathrm{~m}$ entre fileiras x 0,6 m entre as plantas. Foram utilizadas 14 plantas por parcelas de $5,0 \mathrm{~m}$, sendo que somente 10 plantas constituíram a parcela útil.

No ano de 2015 foi realizado o cultivo de abobrinha italiana e após seu cultivo a área permaneceu em pousio até o início de cultivo do quiabeiro em 2016. No ano de 2016, no início do mês de agosto, iniciou-se o transplante das mudas transcorrendo e finalizando o ciclo como ocorreu no ano de 2014. Não houve preparo do solo e reforma dos canteiros em 2016. A adubação e tratos culturais foram os mesmos realizados na primeira safra. A irrigação foi realizada diariamente com lâmina de $3 \mathrm{~mm}$ via gotejamento. As mangueiras autocompensantes com emissor espaçados de 0,6 m e vazão de $1,51 \mathrm{~h}^{-1}$ foram colocadas nas fileiras.

O manejo de plantas daninhas ocorreu por meio de capina manual. Não foram registrados insetos e patógenos que ocasionassem danos econômicos a cultura do quiabeiro, com exceção de formigas - Atta sexdens rubropilosa. O controle de formigas foi realizado com fipronil aplicados em solução sobre os insetos e na abertura do formigueiro na dosagem de 1,5 g i.a. $\mathrm{L}^{-1}$ de calda de fipronil.

A colheita foi realizada a partir dos 60 dias após o transplante observando frutos com comprimento mínimo de 7,0 cm até que a extremidade final do fruto esteja quebradiça. A colheita foi realizada com frequencia de duas vezes semanais durante 75 dias tendo início no mês de outubro e término em dezembro.
As características avaliadas foram: peso de fruto por planta, peso médio de frutos, número de frutos por planta, produtividade, teor de silício, cálcio, magnésio e $\mathrm{pH}$ do solo. Os frutos foram colhidos, contabilizados e pesados em balança de capacidade mínima de $10 \mathrm{~g}$ e máxima de $10 \mathrm{~kg}$. A produtividade foi determinada após o fim da safra somando-se a pesagem de todas as colheitas. O silício no solo foi determinado com extrator cloreto de cálcio $0,01 \mathrm{~mol} \mathrm{dm}^{-3}$ conforme Pereira et al (2007). Os teores de $\mathrm{Ca}, \mathrm{Mg}$ e o $\mathrm{pH}$ do solo foram determinados de acordo com Embrapa (2011b).

Os dados foram submetidos a análise de variância, e as médias comparadas pelo teste Tukey, a 5\% de probabilidade. Quanto ao efeito das doses de silicato foi realizado a análise de regressão a nível de 5\%. As análises estatísticas foram realizadas pelo programa SISVAR (FERREIRA, 2011).

\section{Resultados e Discussão}

As doses do silicato de cálcio e magnésio sobre o teor de $\mathrm{Si}$ e $\mathrm{pH}$ do solo foram significativas $(\mathrm{P}<0,05)$ ajustando a modelo linear (Figuras $1 \mathrm{~A}$ e $1 \mathrm{~B}$ ). O fornecimento de 4,0 $\mathrm{t} \mathrm{ha}^{-1}$ de silicato de cálcio e magnésio incorporado ao solo possibilitou o aumento do teor de silício em $92 \%$ alcançando $15 \mathrm{mg} \mathrm{dm}^{-3}$. A partir da mesma dose de silicato o $\mathrm{pH}$ foi de 6,8 representando um aumento de $19 \%$ comparado ao pH de 5,7 em que não foi aplicado o silicato. Isso mostra o aumento da disponibilidade de Si no solo e a neutralização da acidez trocável $\left(\mathrm{Al}^{+3}\right)$ e parte da acidez ativa $\left(\mathrm{H}^{+}\right)$. Silva et al. (2014) trabalhando com Brachiaria ruziziensis L. observaram o aumento do $\mathrm{pH}$ do solo utilizando doses de 0 a $3,2 \mathrm{t} \mathrm{ha}^{-1}$ de silicato de cálcio e magnésio, o mesmo saindo de 6,08 para 6,73 . 

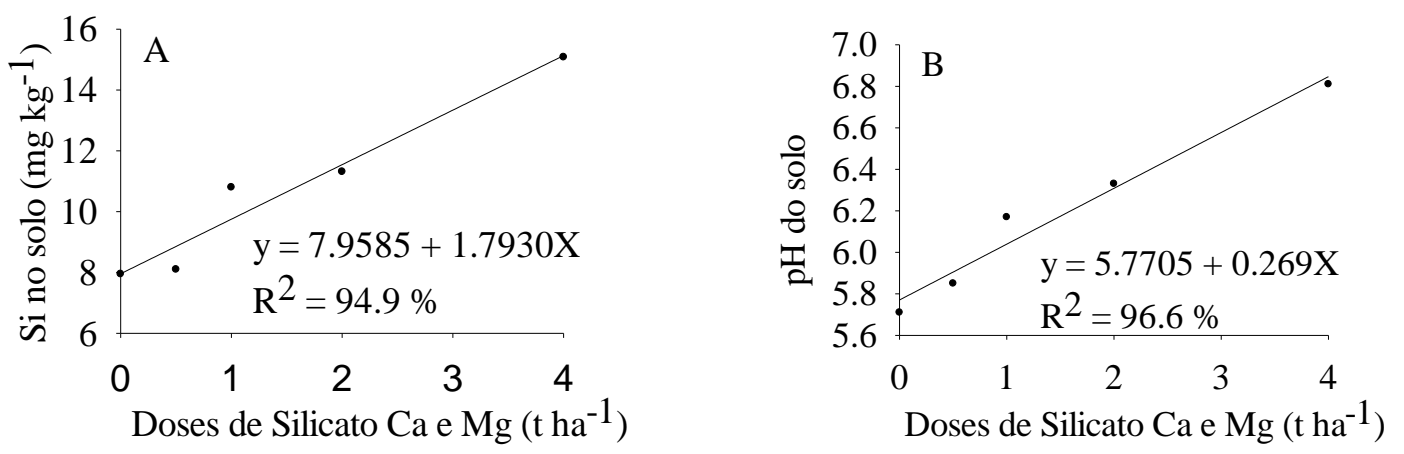

Figura 1. Quantidade de Si no solo (A) e valores do pH (B) e em função de doses de silicato de cálcio e magnésio.

Korndörfer et al. (1999) concluíram que a aplicação de silicato de cálcio e magnésio garante aumentos significativos lineares na redução da acidez do solo, nos teores de $\mathrm{Ca}$ e $\mathrm{Mg}$ trocáveis e nos teores de Si no solo.

A quantidade de cálcio e magnésio no solo, após o cultivo do quiabeiro aumentou gradativamente de acordo com o crescente fornecimento das doses aplicadas de silicato (Figura 2). O uso de fontes corretivas de acidez do solo fornecem nutrientes como $\mathrm{Ca}$ e $\mathrm{Mg}$, aumentando assim os níveis destes nutrientes e a saturação de bases do solo, além disso o silicato de cálcio e magnésio também promovem a neutralização do $\mathrm{Al}$ trocável e podem causar toxidez às plantas (CAIRES; JORIS, 2016). A redução da acidez do solo acarreta maior disponibilização do P lábil na solução do solo (NOVAIS et al., 2007) e redução do poder tampão da matéria orgânica do solo (EBELING et al., 2008).

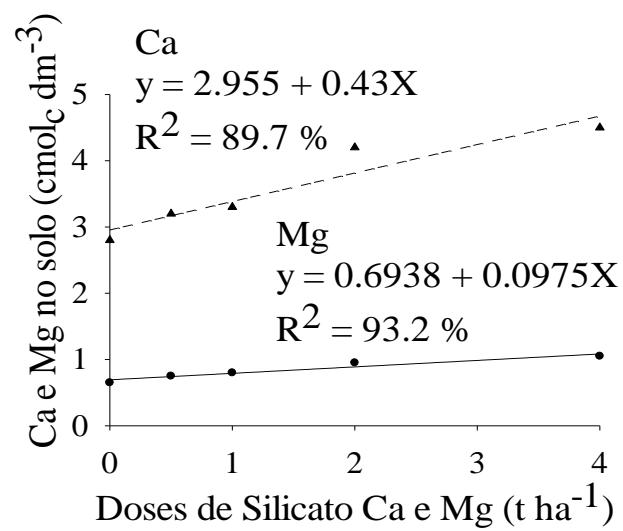

Figura 2. Efeito das doses de silicato de cálcio $(\mathrm{Ca})$ e magnésio $(\mathrm{Mg})$ nos teores de $\mathrm{Ca}$ e $\mathrm{Mg}$ no solo.

O efeito de doses do silicato de cálcio e magnésio sobre o quiabeiro não foi significativo $(\mathrm{P}>0,05)$ para nenhuma das características agronômicas do rendimento, exceto o peso médio dos frutos (Tabela 3). O menor peso médio dos frutos colhidos no ano de 2016 é atribuído à menor taxa de crescimento dos frutos em função da temperatura. A colheita no ano de 2016 teve seu iniciou em meados do mês de agosto; a colheita da safra de 2014 no mês de setembro. A média de temperatura para o mês de setembro de 2014 foi de $24^{\circ} \mathrm{C}$, maior que a média para o mês de agosto de 2016 de 19 ${ }^{\circ} \mathrm{C}$. O quiabeiro, cultura exigente em calor, possui melhor desenvolvimento em temperaturas entre 21 a $25^{\circ} \mathrm{C}$, com médias máximas de $35^{\circ} \mathrm{C}$ e mínimo $1825^{\circ} \mathrm{C}$. (SONNENBERG; SILVA, 2002).

$\mathrm{O}$ quiabeiro não apresentou aumento de produtividade em função do aumento de doses de silicato de cálcio e magnésio. A ausência de resposta do quiabeiro à adição do silicato pode estar relacionada à boa condição inicial do solo. A acidez do solo com pH em 5,8, bons teores de $\mathrm{Ca}$ e $\mathrm{Mg}$ (tabela 1) é um indicativo de boa fertilidade do solo.

Rodrigues et al. (2011), apresentam aumento de rendimento de grãos de arroz e teores de silício na planta. Tais benefícios são consequências de melhoria dos atributos químicos do solo como o $\mathrm{pH}, \mathrm{Ca}, \mathrm{Mg}$ e Si. Souza et al. (2015) verificaram melhor velocidade de emergência e crescimento das plântulas de milho com a aplicação de silicato de cálcio e magnésio. Santana et al. (2015) não observaram efeitos significativos na produtividade de massa verde e massa seca do capim andropogon com a utilização do silicato de cálcio e magnésio, contendo $38 \%$ de $\mathrm{CaO} ; 11 \%$ de $\mathrm{MgO} ; 23 \%$ de $\mathrm{SiO} 2$ e $86 \%$ de poder relativo de neutralização total. Oliveira et al. (2015) observaram boa resposta nas características agronômicas e aumento da massa e vigor das sementes das cultivares de soja BMX turbo RR, tudo isso com a aplicação de silício via solo através da cinza da casca de arroz carbonizada como fonte de silício.

O bom manejo do solo visa garantir condições ideais de cultivo, porém para se obter esse resultado é necessário a adoção de boas práticas de uso do solo e cultivo. Desta forma, deve-se atentar ao uso indiscriminado de corretivos no solo na hora do cultivo tais como o calcário, silicatos e escórias; o uso em excesso de corretivo da acidez do solo poderá provocar dispersão de argilas e desagregação do solo deteriorando sua estrutura física (CASTRO et al., 2011). Pode-se adotar o uso rotacionado dos corretivos contendo silicatos visando manter níveis desejáveis de matéria orgânica e cobertura do solo. 
Tabela 3. Peso de frutos por planta, peso médio de frutos, número de frutos por planta e produtividade de quiabeiro sob doses de silicato de cálcio e magnésio em 2014 e 2016

\begin{tabular}{|c|c|c|c|c|c|c|}
\hline \multirow{2}{*}{ Ano } & \multicolumn{6}{|c|}{ Doses de silicato de Cálcio e Magnésio $\left(\mathrm{t} \mathrm{ha}^{-1}\right)$} \\
\hline & 0,0 & 0,5 & 1,0 & 2,0 & 4,0 & Média \\
\hline \multicolumn{7}{|c|}{ Peso de frutos por planta $(\mathrm{g})$} \\
\hline 2014 & 750 & 773 & 698 & 838 & 884 & $788 \mathrm{~A}$ \\
\hline 2016 & 697 & 643 & 665 & 707 & 734 & $689 \mathrm{~A}$ \\
\hline \multicolumn{7}{|c|}{$\mathrm{DMS}=199 ; \mathrm{CV}_{\mathrm{Ano}}(\%)=34.43$} \\
\hline \multicolumn{7}{|c|}{ Peso médio de frutos (g) } \\
\hline 2014 & 22.2 & 23.0 & 22.7 & 21.4 & 22.8 & $22.4 \mathrm{~B}$ \\
\hline 2016 & 18.4 & 17.6 & 17.5 & 17.7 & 18.1 & $17.9 \mathrm{~A}$ \\
\hline \multicolumn{7}{|c|}{$\mathrm{DMS}=3.55 ; \mathrm{CV}_{\text {Ano }}(\%)=22.41$} \\
\hline \multicolumn{7}{|c|}{ Número de frutos por planta (unidades) } \\
\hline 2014 & 33.5 & 34.9 & 31.3 & 38.1 & 39.1 & $35.4 \mathrm{~A}$ \\
\hline 2016 & 37.8 & 37.5 & 38.4 & 40.0 & 40.5 & $38.9 \mathrm{~A}$ \\
\hline \multicolumn{7}{|c|}{$\mathrm{DMS}=4.98 ; \mathrm{CV}_{\mathrm{Ano}}(\%)=17.09$} \\
\hline \multicolumn{7}{|c|}{ Produtividade $\left(\mathrm{t} \mathrm{ha}^{-1}\right)$} \\
\hline 2014 & 11.2 & 11.6 & 10.4 & 12.5 & 13.2 & $11.8 \mathrm{~A}$ \\
\hline 2016 & 9.9 & 10.2 & 9.9 & 10.1 & 10.0 & $10.0 \mathrm{~A}$ \\
\hline \multicolumn{7}{|c|}{$\mathrm{DMS}=2.66 ; \mathrm{CV}_{\mathrm{Ano}}(\%)=31.05$} \\
\hline
\end{tabular}

${ }^{1}$ Médias seguidas por letras distintas na coluna, diferem entre si pelo Teste de Tukey a 0,05 de significância.

A produtividade de $13,26 \mathrm{t} \mathrm{ha}^{-1}$ alcançada com a maior dose de silicato de $\mathrm{Ca}$ e $\mathrm{Mg}$ está abaixo da citada por Filgueira (2008) que destaca uma boa produtividade de 15 a 20 t ha $^{-1}$ cultivado nas regiões Sudeste e Sul. Na região da Paraíba, um estudo realizado por Oliveira et al. (2014) verificaram baixa produtividade de 4,0 $\mathrm{t} \mathrm{ha}^{-1}$ do quiabeiro, respondendo a adubação orgânica e sem a presença de NPK. Constatou-se que a cultura do quiabo reagiria melhor com uma adição de NPK juntamente com matéria orgânica. Para a cultura do quiabeiro a interação clima, planta e solo e uso adequado de fertilizantes pode influenciar positivamente. A cultura do quiabeiro tem uma boa produção com o plantio a partir do mês de agosto (SONNENBERG; SILVA, 2002) visto que possui um ciclo de aproximadamente 400 dias (FILGUEIRA, 2008).

\section{Conclusões}

Não há acréscimos nos componentes do rendimento e produtividade do quiabeiro com o fornecimento de silicato de cálcio e magnésio em solo de alta fertilidade.

$\mathrm{O}$ silicato de cálcio e magnésio reduz a acidez do solo e aumenta a disponibilidade de $\mathrm{Ca}, \mathrm{Mg}$ e $\mathrm{Si}$ no solo.

\section{Agradecimentos}

À Agronelli pelo fornecimento do produto Agrosilício Plus $^{\circledR}$ ao IFGoiano - Campus Morrinhos.

\section{Referências Bibliográficas}

BACHEGA, L. P. S.; CARVALHO, L. B.; BIANCO, S.; CECÍlIO FILHO, A. B. Período de interferência de plantas daninhas na cultura do quiabo. Planta Daninha, Viçosa,
MG, v. 31, n. 1, p. 63, 2013. Disponível em: <https://repositorio.unesp.br/bitstream/handle/11449/978/S010 $0-83582013000100007$. pdf? sequence $=1$ \&isAllowed $=\mathrm{y}$.

Acesso em: 16 dez 2017

BARBOSA FILHO, M. P.; SNYDER, G. H.; FAGERIA N. K.; DATNOFF L. E.; SILVA, O. F. Silicato de cálcio como fonte de silício para o arroz de sequeiro. Revista Brasileira de Ciências do Solo, Viçosa, MG, v. 25, n. 2, p. 325-330, 2001. Disponível em: <http://www.scielo.br/pdf/rbcs/v25n2/09.pdf>. Acesso em: 19 de abr. 2017.

BARBOSA, N. C.; VENÂNCIO RICARDO.; ASSIS, M. H. S.; PAIVA, J. B.; CARNEIRO, M. A. C.; PEREIRA, H. S. Formas de aplicação de silicato de cálcio e magnésio na cultura do sorgo neossolo quartzarênico de cerrado. Goiânia, GO, v. 38, n. 4, p. 290-291, 2008. Disponível em: <https://www.revistas.ufg.br/pat/article/viewFile/3861/4294>. Acesso em: $17 \mathrm{dez} 2017$.

CAIRES, E. F.; JORIS, H. A. W. Uso de corretivos granulados na agricultura. IPNI - International Plant Nutrition Institute, Piracicaba-SP, n 154, p.17 - 21, 2016. Disponível em: <http://www.ipni.net/publication/iabrasil.nsf/issue/IA-BRASIL-2016-

156? OpenDocument\&toc=0>. Acesso 19 jan. 2017.

CAMARGO, M. S. Efeito do silício na tolerância das plantas aos estresses bióticos e abióticos, Informações Agronômicas, Piracicaba-SP, n. 155, p. 1-8, 2016. Disponível em: <http://www.ipni.net/publication/ia-brasil.nsf/issue/IA-

BRASIL-2016-156?OpenDocument\&toc=0>. Acesso em: 19 jan. 2017.

CAMARGO, M. S.; KORNDÖRFER, G. P.; PEREIRA, H. S. Solubilidade do silício em solos: influência do calcário e ácido silícico aplicados. Campinas-SP, v. 66, n. 4, p. 637647, 2007. Disponível em: <http://www.scielo.br/pdf/brag/v66n4/14.pdf>. Acesso em: 17 abr. 2017

CASTRO, G. S. A.; CAlONEGO, J. C.; CRUSCIOL, C. A. C. Propriedades físicas do solo em sistemas de rotação de culturas conforme o uso de corretivos da acidez. Pesquisa 
Agropecuária Brasileira. Brasília-DF, v. 46, n. 12, p. 16901698, 2011. Disponível em: <https://seer.sct.embrapa.br/index.php/pab/article/view/10362 >. Acesso em: 12 dez. 2016.

CORREIA, L. G.; AVELAR FILHO, J. A.; NAGAI, H. Quiabo. In: RIBEIRO, A. C.; GUIMARÃES, P. T. G.; ALVAREZ V., V. H. (Ed.). Recomendações para o uso de corretivos e fertilizantes em Minas Gerais - $\mathbf{5}^{\text {a }}$ aproximação. Viçosa, MG: Comissão de fertilidade do solo do Estado de Minas Gerais, 1999. p. 25-32.

EMBRAPA. EMPRESA BRASILEIRA DE PESQUISA AGROPECUÁRIA. Catálogo Brasileiro de Hortaliças. Saiba como plantar e aproveitar 50 das espécies mais comercializadas no País. Brasília-DF: Embrapa Hortaliças, 2011a, 60 p.

EMBRAPA. EMPRESA BRASILEIRA DE PESQUISA AGROPECUÁRIA. Manual de métodos de análises de solo. 2 ed. Rio de Janeiro-RJ: Embrapa Solos, 2011b, 230 p.

EMBRAPA. EMPRESA BRASILEIRA DE PESQUISA AGROPECUÁRIA. Sistema Brasileiro de Classificação de Solos. 3. ed. Rio de Janeiro-RJ: Embrapa Solos, 2013. 350 p.

FERREIRA, D. F. Sisvar: a computer statistical analysis system. Ciência e Agrotecnologia, Lavras, v. 35, n.6, p. 10391042, 2011

FILGUEIRA, F. A. R. Novo manual de olericultura: agrotecnologia moderna na produção e na comercialização de hortaliças.3. ed. Viçosa, MG: UFV, 2008. 421 p.

KORNDÖRFER, G. H.; DATNOFF, L. E. Adubação com silício: uma alternativa no controle de doenças da cana-deaçúcar e do arroz. Informações Agronômicas, Piracicaba-SP, sem volume, n. 70, p. 1-3, 1995. Disponível em: $<$ http://www.ipni.net/PUBLICATION/IABRASIL.NSF/0/C681F3735F93590C83257B8E00702AA9/\$ FILE/Page1-3-70.pdf>. Acesso em 10 abr. 2017.

KORNDÖRFER, G. H.; PEREIRA, H. S. e CAMARGO, M. S. Silicatos de Cálcio e Magnésio na Agricultura. 2.ed. Uberlândia-MG: MG-GPSi/ICIAG/UFU, 2002. 24 p. (Boletim Técnico, 1).

KORNDÖRFER, G. H.; ARANTES, V. A.; CORRÊA, G. F.; SNYDER, G. H. Efeito do silicato de cálcio no teor de silício no solo e na produção de grãos de arroz de sequeiro. Revista Brasileira de Ciência do Solo,Viçosa-MG, v. 23, n. 3, p. 635-641, 1999. Disponível em: <http://www.scielo.br/pdf/rbcs/v23n3/17.pdf>. Acesso em 20 abr. 2017.

EBELING, A. G.; DOS ANJOS, L. E. C.; PEREZ, D. V.; PEREIRA, M. G.; VALLADAREZ, G. S. Relação entre acidez e outros atributos químicos em solos com teores elevados de matéria orgânica. Bragantia, Campinas-SP, v. 67, n. 2, p. 429-439, 2008. Disponível em: <http://www.redalyc.org/articulo.oa?id=90867219>. Acesso em 28 dez. 2017.

LANA, R. M. Q.; KORNDÖRFER, G. H.; ZANÃO JÚNIOR, L. A.; SILVA, A. F.; LANA, A. M. Q. Efeito do silicato de cálcio sobre a produtividade e acumulação de silício no tomateiro. Bioscience Journal, Uberlândia-MG, v. 19, n. 2, p.15-20, 2003

NOVAIS, R. F.; ALVAREZ V., V. H.; BARROS, N. F.; FONTES, R. L.; CANTARUTTI, R. B.; NEVES, J. C. L. Fertilidade do Solo. Viçosa-MG: Sociedade Brasileira de Ciência do Solo, 2007. 1017 p.

OLIVEIRA, A. P.; SILVA, O. P. R.; SILVA. J. A.; SILVA, D. F.; FERREIRA, D. T. A.; PINHEIRO, S. M. G. Produtividade do quiabeiro adubado com esterco bovino e NPK. Revista Brasileira de Engenharia Agrícola e Ambiental. Campina Grande-PB, v. 18, n. 10, p. 989-993, 2014.

OLIVEIRA, S.; LEMES, E. S.; MENEGHELLO, G. E.; TAVARES, L. C.; BARROS, A. C. S. A. Aplicação de silício via solo no rendimento e na qualidade fisiológica de sementes de soja. Semina: Ciências Agrárias, Londrina-PR, v. 36, n. 5 , p. 3029-3042, 2015. Disponível em: <http://www.redalyc.org/articulo.oa?id=445744151009>. Acesso em 20 mai. 2017.

PEREIRA, H. S.; BARBOSA, N. C.; CARNEIRO, M. A. C.; KORNDÖRFER, G. H. Avaliação de fontes e de extratores de silício no solo. Pesquisa Agropecuária Brasileira BrasíliaDF, v. 42, n. 2, p.239-247, 2007

RODRIGUES, F. A.; OLIVEIRA, L. A.; KORNDÕRFER, A. P.; KORNDÕRFER, G. H. Silício: um elemento benéfico e importante para as plantas. Informações Agronômicas, Piracicaba-SP, n. 134, p. 14-20, 2011. Disponível em: $<$ http://www.ipni.net/publication/ia-

brasil.nsf/0/66D3EE234A3DA5CD83257A8F005E858A/\$FIL E/Page14-20-134.pdf>. Acesso em: 19 jan. 2017.

SANTANA, C. S,; SANTOS, L. S.; MORAIS, G.; FERNANDES, L. A.; GERASEEV, L. C. Produtividade e valor nutritivo do capim-andropogon adubado com silicato de cálcio e magnésio, Boletim de Indústria Animal, Nova Odessa-SP, v. 72, n. 4, p. 290-297, 2015. Disponível em: <http://www.iz.sp.gov.br/pdfsbia/1450723891.pdf〉. Acesso em 26 abr. 2017.

SILVA, W. B.; BARCELOS, F. P; SICHOCKI, D.; SILVA, G. M. C. Uso do silicato de cálcio na correção da acidez do solo no desenvolvimento da Brachiaria ruziziensi $L$. Perspectiva online. Ciências Exatas e Engenharia, Campos dos Goytacazes-RJ, v. 10, n. 4, p. 1-11, 2014.

SONNENBERG, P. E.; SILVA, N. F. Desenvolvimento e produção do quiabeiro em função das datas de plantio. Pesquisa Agropecuária Tropical, Goiânia-GO, v. 32, n. 1, p. 33-37, 2002. Disponível em: <https://www.revistas.ufg.br/pat/article/view/2438>.

SOUZA, J. P. F.; MARTINS, G. L. M.; PEREIRA, A. C.; BINOTTI, F. F. S; MARUYAMA, W. I. Efeito de silicato de cálcio e magnésio no crescimento de milho transgênico. Revista de Agricultura Neotropical, Cassilândia-MS, v. 2, n. 3 , p. 13-17, 2015. Disponível em: <https://periodicosonline.uems.br/index.php/agrineo/article/vi ew/280/397>. Acesso em: 16 jun. 2017. 